\title{
ĐẶC ĐIỂM LÂM SÀNG, CẬN LÂM SÀNG CơN TIM NHANH Ở TRẺ EM TẠI BệNH VIỆN NHI TRUNG ƯơNG
}

\author{
Hoàng Văn Toàn', Đặng Thị Hải Vân², Nguyễn Thanh Hải ${ }^{3}$ \\ 1. Bệnh viện Sản Nhi Nghệ An, 2. Trường Đại học Y Hà Nội, 3. Bệnh viện Nhi Trung ương
}

\begin{abstract}
TÓM TẮT
Mục tiêu: Mô tả đặc điểm lâm sàng, cận lâm sàng của cơn nhịp nhanh thất và trên thất ở trẻ em tại Bệnh viện Nhi Trung ương. Đối tượng và phương pháp nghiên cứu: Mô tả 89 trẻ có cơn tim nhanh tại Bệnh viện Nhi Trung ương từ tháng 3/2019-6/2020. Kết quả: Trong 89 trẻ có cơn nhịp tim nhanh, 71 trẻ nhịp nhanh kịch phát trên thất (supraventricular tachycardia-SVT) chiếm $79,8 \%$ và 18 trẻ nhịp nhanh thất (ventricular tachycardia-VT) chiếm 20,2\%. Trẻ dưới 12 tháng chiếm tỷ lệ 42,7\%. Có 36/89 trẻ có bệnh lý kèm theo, trong đó có 19/89 trẻ mắc tim bẩm sinh, chiếm $21,3 \%$. SVT có suy tuần hoàn ít hơn ( $18,3 \%$ so với $55,6 \% ; p=0,003)$, tân số tim nhanh hơn $(238,1 \pm 31,0$ so với $209,6 \pm 34,0 ; p<0,001)$, chỉ số phân suất tống máu thất trái (LVEF) giảm ít hơn (18,3\% so với $44,4 \%, p<0,029)$, thời gian QRS ngắn hơn $(77,9 \pm 23,0$ so với $131,4 \pm 23,6 ; p$ $<0,001)$ so với VT. Kết luận: SVT chiếm tỷ lệ cao, có tân số tim nhanh hơn, nhưng suy tuân hoàn thấp hơn so với VT và thường gặp ở trẻ nhỏ tuổi hơn. VT chiếm tỷ lệ suy tuần hoàn khá cao và thường găp ở trẻ lớn tuổi hơn.
\end{abstract}

Từ khóa: Nhịp tim nhanh, nhịp nhanh kịch phát trên thất, nhịp nhanh thất.

\section{ABSTRACT \\ CLINICAL AND PARACLINICAL CHARATERISTICS OF PEDIATRIC TACHYCARDIA AT VIETNAM NATIONAL CHILDREN'S HOSPITAL}

Objectives: To describe the clinical and paraclinical characteristics of pediatric supraventricular tarchycardia and ventricular tachycardia at Vietnam National Children's Hospital. Subjects and Method: Descritive study of 89 children who developed tachycardia at Vietnam National Children's Hospital from March 2019 to June 2020. Results: Among 89 children: 71 children had SVT (79.8\%) and 18 children $(20,2 \%)$ had VT. Children aged less than 12 months accouted for 42.7\%. 36/89 children had comorbidities, of which $19 / 89$ children had congenital heart disease, accounted for $21.3 \%$. Comparing to VT, SVT was lesser circulation failure $(18.3 \%$ vs $55.6 \% ; p=0,003)$, higher heart rate $(238.1 \pm 31.0$ vs $209.6 \pm 34.0 ; p<0.001$ ), lesser reduced left ventricular ejection fraction (LVEF) (18.3\% so với $44.4 \%$, $p<0.029)$, shorter QRS period $(77.9 \pm 23.0$ vs $131.4 \pm 23.6 ; p<0.001)$. Conclusion: Comparing to VT, SVT was higher heart rate, lesser circulatory failure, more common in younger children. VT accounted for high circulation failure proportion and was common in older children.

Keywords: Tachycardia, supraventricular tarchycardia, ventricular tachycardia.

Nhận bài: 15-12-2020; Chấp nhận: 10-2-2021

Người chịu trách nhiệm chính: Đặng Thị Hải Vân

Địa chỉ:dthv2004@hotmail.com 


\section{1. ĐẶT VẤN ĐÊ}

Rối loạn nhịp tim là một bệnh lý thường gặp, phức tạp trong thực hành lâm sàng tim mạch, từ những rối loạn nhịp lành tính đến những rối loạn nhịp ác tính và có nhiều nguyên nhân gây ra. Các nghiên cứu trước đây chỉ ra rằng, sốc do rối loạn nhịp tim tập trung ở hai loại: nhịp nhanh kịch phát trên thất (SVT) và nhịp nhanh thất (VT) [1],[2]. Cơn nhịp nhanh thường xuất hiện đột ngột rồi tự hết hoặc có thể kéo dài. ở trẻ em, triệu chứng của cơn tim nhanh thường mơ hồ, khó nhận biết, tiến triển nhanh và nặng hơn người lớn. Trẻ lớn thường có biểu hiện đau tức ngực, hồi hộp, trẻ nhỏ chỉ có biểu hiện chung như bú kém, kích thích quấy khóc [3], nặng hơn thường có biểu hiện ngủ nhiều hay lơ mơ, da tái, tiểu ít, sốc tim. Vì vậy việc chẩn đoán và điều trị cơn nhịp nhanh ở trẻ nhỏ khó khăn hơn nhiều so với người lớn. Trên thế giới và tại Việt Nam đã có rất nhiều nghiên cứu về vấn đề này nhưng chủ yếu ở người lớn. Các nghiên cứu ở trẻ em rất ít. Do đó chúng tôi nghiên cứu đề tài này với mục tiêu: Mô tả đặc điểm lâm sàng, cận lâm sàng của cơn nhịp nhanh thất và trên thất ở trẻ em tại Bệnh viện Nhi Trung ương từ 3/2019-6/2020.

\section{2. ĐốITƯợNG VÀ PHƯớNG PHÁP NGHIÊN CỨU}

\section{1. Đối tượng nghiên cứu}

Tất cả các bệnh nhân nhập viện điều trị tại Bệnh viện Nhi trung ương từ $1 / 3 / 2019$ đến 30/6/2020 có tần số tim nhanh được xác định ít nhất trên điện tâm đồ hoặc holter điện tim, tuổi từ 0 - 15, loại trừ các loại rối loạn nhịp nhanh xoang, rung nhĩ, cuồng nhĩ, nhanh nhĩ đa ổ, rung thất, cuồng thất và những trẻ đã phẫu thuật, can thiệp tim mạch tính đến thời điểm nghiên cứu.

\subsection{Phương pháp nghiên cứu}

Mô tả tiến cứu, chọn mẫu thuận tiện

Tất cả các trẻ chẩn đoán có cơn tim nhanh đủ tiêu chuẩn nghiên cứu được theo dõi liên tục trong thời gian nghiên cứu, đánh giá về các rối loạn nhịp tim nhanh dựa trên tiền sử, lâm sàng, điện tâm đồ bề mặt, holter điện tim 24 giờ, thăm dò điện sinh lý để chẩn đoán phân loại nhịp tim nhanh.

2.3. Phân tích và số liệu: Nhập và phân tích số liệu bằng phần mềm thống kê SPSS 20.0.

\section{KẾT QUẢ NGHIÊN CỨU}

Trong thời gian từ tháng 3 năm 2019 đến tháng 6 năm 2020 có 89 bệnh nhân rối loạn nhịp tim nhanh tại Bệnh viện Nhi Trung ương đủ tiêu chuẩn được đưa vào nghiên cứu.

\section{1. Đặc điểm chung của nghiên cứu}

Trong 89 bệnh nhân nghiên cứu, có 71/89 được phân loại nhịp nhanh trên thất chiếm 79,8\%, 18 bệnh nhân còn lại thuộc nhóm nhịp nhanh thất chiếm $20,2 \%$.

Trong 71 bệnh nhân nhịp nhanh trên thất có 9 $(12,7 \%)$ bệnh nhân được chẩn đoán nhịp nhanh vào lại nút nhĩ thất, 10 (14,1\%) bệnh nhân được chẩn đoán nhịp nhanh nhĩ, 27 (38,0\%) bệnh nhân được chẩn đoán nhịp nhanh vào lại nhĩ thất và 25 (35,2\%) bệnh nhân chưa chẩn đoán xác định được.

Tuổi bệnh nhân được phân thành 3 nhóm, nhóm dưới 12 tháng có tỷ lệ cao nhất (42,7\%), nhóm từ 12 tháng đến 60 tháng chiếm 25,8\% và nhóm trên 60 tháng chiếm 31,5\%. Độ tuổi trung bình của nhóm nhịp nhanh thất cao hơn nhóm nhịp nhanh trên thất $(39,1 \pm 49,4$ so với $64,3 \pm 57,6), p=0,038$.

Tỷ lệ giới nam và nữ là 2,08. Không có sự khác biệt về giới giữa VT và SVT.

Có tiền căn rối loạn nhịp của nhóm nhịp nhanh trên thất là $44,4 \%$, của nhóm nhịp nhanh thất là $57,7 \%$ và chung là $55,1 \%$. 


\section{2. Đặc điểm lâm sàng}

Bảng 1. Biểu hiện lâm sàng trong cơn nhịp tim nhanh

\begin{tabular}{|c|c|c|c|c|c|}
\hline \multirow{2}{*}{\multicolumn{2}{|c|}{ Biểu hiện lâm sàng }} & $\begin{array}{l}\text { Nhịp nhanh trên thất } \\
\qquad n=71\end{array}$ & $\begin{array}{l}\text { Nhịp nhanh thất } \\
n=18\end{array}$ & $\begin{array}{l}\text { Tổng } \\
\mathrm{N}=89\end{array}$ & \multirow{2}{*}{$\mathbf{p}$} \\
\hline & & n (\%) & n (\%) & $\mathbf{N}(\%)$ & \\
\hline \multirow{2}{*}{ Suy tuần hoàn } & Có & $13(18,3)$ & $10(55,6)$ & $23(25,8)$ & \multirow{2}{*}{$0,003^{b}$} \\
\hline & Không & $58(81,7)$ & $8(44,4)$ & $66(74,2)$ & \\
\hline \multirow{2}{*}{ Kích thích, quấy khóc } & Có & $44(62,0)$ & $8(55,6)$ & $52(58,4)$ & \multirow{2}{*}{$0,193 a$} \\
\hline & Không & $27(38,0)$ & $10(44,4)$ & $37(41,6)$ & \\
\hline \multirow{2}{*}{ Hồi hộp, tức ngực $n=32$} & Có & $20(13,0)$ & $9(100)$ & $29(69,0)$ & \\
\hline & Không & $3(87,0)$ & 0 & $3(31,0)$ & \\
\hline
\end{tabular}

Nhận xét: Tỷ lệ trẻ có suy tuần hoàn trong cơn tim nhanh thất là 55,6\% cao hơn có ý nghĩa thống kê so với nhóm nhịp nhanh trên thất 18,3\%, $\mathrm{p}=0,003$.

Bảng 2. Các bệnh lý kèm theo

\begin{tabular}{|l|c|c|c|}
\hline \multirow{2}{*}{ Bệnh kèm theo } & $\begin{array}{c}\text { Nhịp nhanh trên thất } \\
\mathbf{n = 7 1}\end{array}$ & $\begin{array}{c}\text { Nhịp nhanh thất } \\
\mathbf{n = 1 8}\end{array}$ & $\begin{array}{c}\text { Tổng } \\
\mathbf{N}=\mathbf{8 9}\end{array}$ \\
\cline { 2 - 4 } & $\mathbf{n}(\%)$ & $\mathbf{n}(\%)$ & $\mathbf{N}(\%)$ \\
\hline Bệnh tim bẩm sinh & $17(23,9)$ & $2(11,1)$ & $19(20,9)$ \\
\hline Viêm cơ tim & $1(1,4)$ & $4(22,2)$ & $5(5,5)$ \\
\hline TDMNT & $2(2,8)$ & 0 & $2(2,2)$ \\
\hline Các bệnh khác & $8(11,3)$ & $2(11,1)$ & $10(11,0)$ \\
\hline Không & $43(60,6)$ & $10(55,6)$ & $55(60,4)$ \\
\hline
\end{tabular}

Nhận xét: $34 / 89$ trẻ có bệnh kèm theo chiếm 39,6\%, trong đó tim bẩm sinh chiếm tỷ lệ cao nhất là $20,9 \%$.

\section{3. Đặc điểm cận lâm sàng}

Bảng 3. Đặc điểm điện tâm đồ trong cơn tim nhanh

\begin{tabular}{|l|c|c|c|c|}
\hline \multicolumn{1}{|c|}{ ECG trong cơn } & $\begin{array}{c}\text { Nhịp nhanh trên thất } \\
\mathbf{n}=71\end{array}$ & $\begin{array}{c}\text { Nhịp nhanh thất } \\
\mathbf{n}=18\end{array}$ & $\begin{array}{c}\text { Tổng } \\
\mathbf{N}=\mathbf{8 9}\end{array}$ & $\mathbf{p}$ \\
\hline Nhịp tim & $237,3 \pm 30,5$ & $209,6 \pm 34,1$ \\
$\bar{X} \pm$ SD & $(167-300)$ & $(160-300)$ & $231,8 \pm 32,9$ & 0,004 \\
(min - max) & $77,2 \pm 23,0$ & $160-300)$ & \\
\hline Thời gian QRS & $(46-180)$ & $(95-180)$ & $87,9 \pm 31,6$ & $<0,001$ \\
$\begin{array}{l}\text { X } \pm \text { SD ms } \\
\text { (min - max) }\end{array}$ & $(46-180)$ & 23,6 & \\
\hline
\end{tabular}

Nhận xét: Tần số tim của SVT cao hơn VT, sự khác biệt này có ý nghĩa thống kê với $p=0,004$. Thời gian QRS ở VT lớn hơn SVT, sự khác biệt có ý nghĩa thống kê với $\mathrm{p}<0,001$. 
TẠP CHÍ NHI KHOA 2021, 14, 1

Bảng 4. Đặc điểm điện tâm đồ trong cơn tim nhanh trên thất

\begin{tabular}{|c|c|c|c|c|c|c|}
\hline \multirow[t]{2}{*}{$\begin{array}{l}\text { Đặc điểm điện tâm đồ } \\
\text { trong cơn của SVT }\end{array}$} & $\begin{array}{c}\text { Vào lại nút } \\
\text { nhĩ thất } \\
n=9\end{array}$ & $\begin{array}{c}\text { Vào lại nhĩ } \\
\text { thất } \\
n=27\end{array}$ & $\begin{array}{l}\text { Nhanh nhĩ } \\
n=10\end{array}$ & $\begin{array}{c}\text { Chưa xác } \\
\text { định } \\
n=25\end{array}$ & \multirow[t]{2}{*}{$\mathbf{p}$} & $\begin{array}{c}\text { Tổng } \\
\mathrm{N}=71\end{array}$ \\
\hline & n (\%) & n (\%) & n (\%) & n (\%) & & n (\%) \\
\hline Xác định sóng P & $\begin{array}{c}1 \\
11,1\end{array}$ & $\begin{array}{c}4 \\
14,8\end{array}$ & $\begin{array}{c}9 \\
90,0\end{array}$ & $\begin{array}{c}11 \\
44,0\end{array}$ & $<0,001$ & $\begin{array}{c}25 \\
35,2\end{array}$ \\
\hline $\begin{array}{l}\text { ST } \\
\text { Chênh }\end{array}$ & 0 & $\begin{array}{c}11 \\
40,7\end{array}$ & $\begin{array}{c}5 \\
50,0\end{array}$ & $\begin{array}{c}4 \\
16,0\end{array}$ & $0,045^{b}$ & $\begin{array}{c}20 \\
28,2\end{array}$ \\
\hline ST đảo hướng & 0 & $\begin{array}{c}5 \\
18,5\end{array}$ & $\begin{array}{c}5 \\
50,0\end{array}$ & $\begin{array}{c}4 \\
16,0\end{array}$ & $0,048^{b}$ & $\begin{array}{c}14 \\
19,7\end{array}$ \\
\hline $\begin{array}{l}\text { Sóng QRS } \\
\text { rộng }\end{array}$ & 0 & $\begin{array}{c}3 \\
11,1\end{array}$ & $\begin{array}{c}2 \\
20,0\end{array}$ & 0 & & $\begin{array}{c}5 \\
7,0\end{array}$ \\
\hline
\end{tabular}

${ }^{b}$ Fisher Exact Test

Nhận xét: Tỷ lệ bệnh nhân xác định được sóng $\mathrm{P}$ trên điện tâm đồ trong cơn tim nhanh trên thất là $35,2,0 \%$ chủ yếu ở nhóm nhịp nhanh nhĩ. 93,2\% bệnh nhân nhịp nhanh trên thất có QRS hẹp. Chỉ có 7,0\% bệnh nhân nhịp nhanh trên thất có QRS rộng.

Bảng 5. Đặc điểm điện tâm đồ trong cơn tim nhanh thất

\begin{tabular}{|l|c|c|}
\hline \multicolumn{1}{|c|}{ Đặc điểm điện tâm đồ trong cơn nhịp nhanh thất } & Số bệnh nhân n=18 & Tỷ lệ \% \\
\hline Không có RS ở các chuyển đạo trước tim & 5 & 27,8 \\
\hline Khoảng R đến S >100ms ở một chuyển đạo trước tim & 10 & 55,5 \\
\hline Phân ly nhĩ thất, tần số thất > tần số nhĩ & 9 & 50,0 \\
\hline Thời gian QRS >160ms & 10 & 55,5 \\
\hline
\end{tabular}

Nhận xét: Trong 18 trẻ được chẩn đoán nhịp nhanh thất, khi phân tích điện tâm đồ trong cơn theo tiêu chuẩn Brugada, thời gian $Q R S>160 \mathrm{~ms}$ và khoảng $R$ đến $S>100 \mathrm{~ms}$ ở một chuyển đạo trước tim chiếm tỷ lệ cao nhất 55,5\%.

Bảng 6. Đặc điểm điện tâm đồ ngoài cơn tim nhanh

\begin{tabular}{|l|c|c|c|}
\hline \multirow{2}{*}{ ECG ngoài cơn } & $\begin{array}{c}\text { Nhịp nhanh trên thất } \\
\mathbf{n}=\mathbf{7 1}\end{array}$ & $\begin{array}{c}\text { Nhịp nhanh trên thất } \\
\mathbf{n}=\mathbf{1 8}\end{array}$ & $\begin{array}{c}\text { Tổng } \\
\mathbf{N}=\mathbf{8 9}\end{array}$ \\
\cline { 2 - 4 } & $\mathbf{n}(\%)$ & $\mathbf{n}(\%)$ & $\mathbf{n}(\%)$ \\
\hline Bình thường & $47(66,1)$ & $11(61,1)$ & $58(65,2)$ \\
\hline WPW & $16(22,4)$ & 0 & $16(18,0)$ \\
\hline Ngoại tâm thu thất & 0 & $4(22,2)$ & $4(4,5)$ \\
\hline Nhịp nhĩ ổ & $6(8,5)$ & $1(11,1)$ & $7(7,9)$ \\
\hline Block A-V độ 1 & $2(2,8)$ & 0 & $2(2,2)$ \\
\hline Block A-V độ 2 & $1(1,4)$ & 0 & $1(1,1)$ \\
\hline H/C nhịp nhanh - chậm & $2(2,8)$ & 0 & $2(2,2)$ \\
\hline QT dài & 0 & $2(11,1)$ & $2(2,2)$ \\
\hline
\end{tabular}

Nhận xét: 65,2\% bệnh nhân có hình ảnh điện tâm đồ ngoài cơn bình thường. Tỷ lệ bất thường điện tim hay gặp nhất là hội chứng WPW. 
Bảng 7. Phân suất tống máu thất trái, nồng độ NT- proBNP và troponin I

\begin{tabular}{|c|c|c|c|c|}
\hline \multicolumn{2}{|c|}{ Các chỉ số } & $\begin{array}{c}\text { Nhịp nhanh trên thất } \\
\text { n (\%) }\end{array}$ & $\begin{array}{c}\text { Nhịp nhanh thất } \\
\text { n (\%) }\end{array}$ & $\mathbf{p}$ \\
\hline \multirow{3}{*}{$\begin{array}{l}\text { Phân suất tống máu } \\
\text { thất trái LVEF (\%) } \\
\mathrm{n}=89\end{array}$} & Giảm & $13(18,3)$ & $8(44,4)$ & \multirow[t]{2}{*}{$0,029^{b}$} \\
\hline & Bình thường & $58(81,7)$ & $10(55,6)$ & \\
\hline & $\overline{\mathrm{X}} \pm \mathrm{SD}(\min -\max )$ & $59,5 \pm 9,2$ & $50,9 \pm 10,7$ & $0,001^{d}$ \\
\hline \multirow{3}{*}{$\begin{array}{l}\text { NT- proBNP pg/mL } \\
n=48\end{array}$} & Tăng & $19(52,8)$ & $10(83,3)$ & \multirow{2}{*}{$0.061^{b}$} \\
\hline & Bình thường & $17(47,2)$ & $2(16,7)$ & \\
\hline & $\begin{array}{l}\text { Trung vị } \\
\text { (tứ phân vị) }\end{array}$ & $\begin{array}{l}340 \\
(132-2266)\end{array}$ & $\begin{array}{l}1069 \\
(527-3006)\end{array}$ & $0,273^{d}$ \\
\hline \multirow{3}{*}{$\begin{array}{l}\text { Troponin Ing/L } \\
n=44\end{array}$} & Tăng & $15(45,5)$ & $8(72,7)$ & \multirow{2}{*}{$0,117^{a}$} \\
\hline & Bình thường & $18(54,5)$ & $3(27,3)$ & \\
\hline & $\begin{array}{l}\text { Trung vị } \\
\text { (tứ phân vị) }\end{array}$ & $\begin{array}{l}0,09 \\
(0,02-0,512)\end{array}$ & $\begin{array}{l}0,21 \\
(0,086-0,546)\end{array}$ & $0,524^{d}$ \\
\hline
\end{tabular}

${ }^{b}$ Fisher Exact Test ${ }^{a}$ Chi-square ${ }^{d}$ Mann-whitney

Nhận xét: Tỷ lệ bệnh nhân có phân suất tống máu giảm ở nhóm rối loạn nhịp nhanh thất là $44,4 \%$, cao hơn nhóm rối loạn nhịp nhanh trên thất $18,3 \%$. Sự khác biệt có ý nghĩa thống kê, $p<0,029$. Chỉ có 48 bệnh nhân được xét nghiệm NT - ProBNP và 44 bệnh nhân được xét nghiệm troponin. Chỉ số NT- prBNP và troponin I được ghi nhận ở bệnh nhân có nhịp nhanh thất cao hơn so với nhóm bệnh nhân có nhịp nhanh trên thất, nhưng sự khác biệt này không có ý nghĩa thống kê.

\section{BÀN LUÂN}

4.1. Phân bố nhịp tim nhanh của nhóm nghiên cứu

Trong 89 trẻ được đưa vào nghiên cứu của chúng tôi, số trẻ được chẩn đoán là SVT chiếm $79,8 \%$ và $V T$ là 18 trẻ chiếm tỷ lệ $20,2 \%$. Kết quả này cũng tương tự với nghiên cứu của Martial $M$. Massin (SVT 84\%, VT 16\%) và một số nghiên cứu trước đó [2],[3].

\subsection{Tuổi}

Trong nghiên cứu của chúng tôi, độ tuổi trung bình của nhóm SVT là 3,2 tuổi, của VT là 5,3 tuổi. Độ tuổi trung bình chung là 3,7 tuổi thấp hơn so với nghiên cứu của Martial M. Massin là 4,7 tuổi [2]. Nguyên nhân do đối tượng nghiên cứu của chúng tôi từ 0 - 15 tuổi, của Martial M. Massin là từ 0 - 18 tuổi. Có sự khác biệt giữa các nhóm tuổi của hai nhóm SVT và VT, $p=0,031$. Độ tuổi hay gặp nhất là trẻ dưới 12 tháng chiếm 44,0\%, điều này cũng phù hợp với $Y$ văn đã mô tả trước đây, cơn nhịp nhanh xảy ra từ rất sớm ngay trong giai đoạn bào thai hoặc một thời gian ngắn sau khi $\sinh [2],[3]$.

\subsection{Giới}

Loạn nhịp tim hay gặp ở trẻ nam hơn trẻ nữ, trong nghiên cứu này tỷ lệ trẻ nam là $67,4 \%$, kết quả này tương tự với nghiên cứu của Martial 
M.Massin (63,2\%) [2] và của Bùi Xuân Vũ $(61,5 \%)$ [1]. Vì cỡ mẫu nghiên cứu nhỏ nên khó kết luận được giới tính có liên quan đến loại cơn nhịp nhanh hay không?

\section{4. Đặc điểm lâm sàng}

Biểu hiện suy tuần hoàn xảy ra ở 23 trẻ, chiếm $25,8 \%$, tỷ lệ này phù hợp với nghiên cứu của Bùi Xuân Vũ $(28,8 \%)$ [1]. Trong đó SVT là $18,3 \%$ thấp hơn nhiều so với VT là $55,6 \%$. Sự khác biệt này có ý nghĩa thống kê, $p=0,003$. Điều này cho thấy trẻ bị VT cần phải can thiệp kịp thời khi xuất hiện cơn.

Kích thích quấy khóc chiếm $58,4 \%$, nguyên nhân do tình trạng thiếu hụt cung lượng tuần hoàn, gây thiếu máu não làm cho trẻ khó chịu. biểu hiện hồi hộp tức ngực ở trẻ lớn cũng được ghi nhận khá cao 69,0\%.

$36 / 89$ trẻ chiếm tỷ lệ $40,4 \%$ có bệnh lý kèm theo. Viêm cơ tim có 5 trẻ, chủ yếu ở nhóm VT 4/5. Tim bẩm sinh 19/89 trẻ chiểm tỷ lệ cao nhất $21,3 \%$, trong đó còn ống động mạch chiếm $5,5 \%[4]$.

\section{5. Đặc điểm cận lâm sàng}

Nhịp tim trung bình của nhịp nhanh chung trong cơn là 231,8 $\pm 32,9$ lần/phút, thay đổi từ 160-300 lần/phút. Nhóm SVT có tần số cao hơn VT $(237,3 \pm 30,5$ so với $209,6 \pm 34,0 ; p=0,004)$. Điều này được lý giải bởi tốc độ dẫn truyền xung động của tâm nhĩ và tâm thất khác nhau. Đối với tầng nhĩ tốc độ dẫn truyền xung động nhanh hơn và cơ chế đường vào lại ngắn hơn so với thất nên tần số sẽ cao hơn tầng thất. Như vậy, nhóm có tần số nhịp tim nhanh hơn không có nghĩa sẽ làm tỷ lệ rối loạn huyết động cao hơn.

Điện tâm đồ trong cơn ghi nhận thời gian QRS ở nhóm SVT trung bình ngắn hơn VT $(77,2 \pm 23,0$ ms so với 131,4 23,$6 ; p<0.001$ ) [3].

Điện tâm đồ trong cơn của nhóm SVT cho thấy xác định được sóng $\mathrm{P}$ ở 25/71 bệnh nhân, tập trung chủ yếu ở nhóm nhịp nhanh nhĩ $(9 / 10)$ và nhóm chưa xác định (11/25), cao hơn nhiều so với nhịp nhanh vào lại nút nhĩ thất và nhịp nhanh vào lại nhĩ thất, sự khác biệt này có ý nghĩa thống kê, $p<0,001$. Thường nhịp nhanh nhĩ luôn xuất hiện sóng $P$ đi trước, nhứng khi có Block $A-V$ sẽ gây ra tình trạng sóng $P$ của phức bộ sau trùng với sóng $S T$ của phức bộ trước nên khó xác định $P$. Tỷ lệ tìm thấy sóng $\mathrm{P}$ ở nhóm chưa xác đinh chiếm tỷ lệ cao chứng tỏ nếu được thăm dò điện sinh lý sẽ cho kết quả nhanh nhĩ khá cao. Sóng ST chênh 20/71 trẻ, tập trung chủ yếu ở nhóm nhịp nhanh vào lại nhĩ thất, sự khác biệt giữa các nhóm có ý nghĩa thống kê. Sóng ST đảo hướng ghi nhân 14/71 trẻ. Phức bộ QRS giãn ghi nhận có 5 trẻ, trong đó có 2 trẻ thuộc nhịp nhanh vào lại nhĩ thất có hình ảnh dẫn truyền lệch hướng, còn lại là block nhánh.

Điện tâm đồ trong cơn nhóm VT, theo phác đồ Brugada ghi nhận có khỏang $R S>100 \mathrm{~ms}$ và $Q R S$ $>160 \mathrm{~ms}$ đều có $10 / 18$ trẻ chiếm tỷ lệ cao nhất, tiếp đến là phân ly nhĩ thất $9 / 18$ và không có dạng RS ở các chuyển đạo trước tim là $5 / 18$. Sở dĩ tỷ lệ $Q R S>160$ ms và $R S>100 m s$ thấp hơn so với nghiên cứu của người lớn [5], vì giới hạn khoảng thời gian của $Q R S$ và $R S$ của trẻ em thấp hơn của người lớn.

Điện tâm đồ ngoài cơn có 58/91 trẻ bình thường, chiếm tỷ lệ $65,2 \%$. Hội chứng Wolff Parkinson - White 16/91 trẻ chiếm tỷ cao nhất trong nhóm điện tim bất thường cũng được ghi nhận của những tác giả khác [6],[7], tiếp đến là nhịp nhĩ ổ và ngoại tâm thu thất. Chúng tôi ghi nhận 2 trẻ có nhịp nhanh - chậm đều thuộc nhóm SVT, 2 trẻ có QT kéo dài thuộc nhóm VT.

Phân suất tống máu (LVEF) giảm ở nhóm VT chiếm tỷ lệ cao hơn SVT (44,4\% so với $18,3 \%)$, sự khác biệt này có ý nghĩa thống kê, $p=0,029$. Kết quả này phụ hợp với triệu chứng suy tuần hoàn trước đó. Chỉ số NT - proBNP và troponin I được đưa vào thăm dò xem có sự khác biệt giữa 2 nhóm SVT và VT nhưng số lượng mẫu nghiên cứu nhỏ nên không thể khẳng định được.

\section{KẾT LUẬN}

Nhịp nhanh kịch phát trên thất chiếm tỷ lệ cao, có tần số tim nhanh hơn, nhưng tỷ lệ rối loạn huyết động, suy tuần hoàn thấp hơn so với VT và 
thường gặp ở trẻ nhỏ tuổi hơn. VT chiếm tỷ lệ ít nhưng rối loạn huyết động, suy tuần hoàn khá cao và thường găp ở trẻ lớn tuổi hơn. Cơn nhịp tim nhanh có tiền sử chiếm tỷ lệ cao chứng tỏ tái phát cơn là đặc điểm thường gặp ở trẻ em.

\section{TÀI LIỆU THAM KHẢO}

1. Bùi Xuân Vũ, Hoàng Trọng Kim (2001). Đặc điểm rối loạn nhịp tim tại Bệnh viện Nhi Đồng 1. Tạp chíY học Thành phố Hồ Chí Minh; 4(5), tr134-142.

2. Massin MM, Benatar A, Rondia G (2008). Epidemiology and Outcome of Tachyarrhythmias in Tertiary Pediatric Cardiac Centers. Cardiology; 111(3): 191-6.

3. Bùi Gio An, Vũ Công Đồng (2009). Đặc điểm chẩn đoán và điều trị cấp cứu rối loạn nhịp tim nhanh ở trẻ em nhập khoa cấp cứu Bệnh viện Nhi Đồng 2. Tạp chí $Y$ học Thành phố Hồ Chí Minh; 13(1),tr 114-120.
4. Batte A., Lwabi P., Lubega S. et al (2016). Prevalence of arrhythmias among children below 15 years of age with congenital heart diseases attending Mulago National Referral Hospital, Uganda. BMC Cardiovasc Disord, 16.

5. Pfammatter J-P, Paul T (1999). Idiopathic ventricular tachycardia in infancy and childhood. Journal of the American College of Cardiology; 33(7): 2067-72.

6. Doniger SJ, Sharieff GQ (2006). Pediatric Dysrhythmias. Pediatric Clinics of North America.; 53(1): 85-105.

\section{Balaguer Gargallo M, Jordan Garcia I, Caritg} Bosch J, (2007). Supraventricular tachycardia in infants and children,An Pediatr (Barc), 67, Aug, 133-8. 